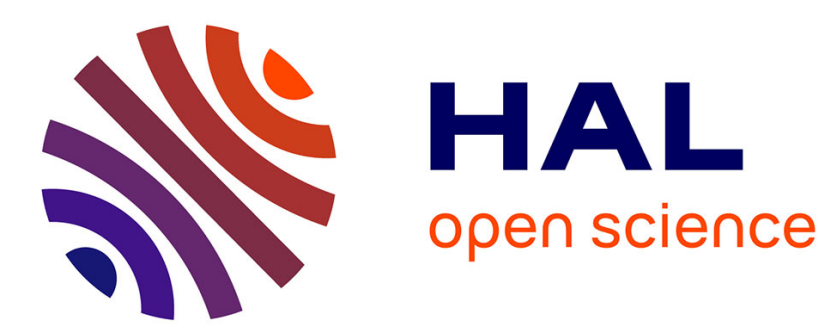

\title{
Observaciones sobre estacionalidad de vuelos de áfidos cubanos y particularmente de Myzus persicae (Sulz.) en cultivo de patata
}

Keyla Perez, Yvon Robert

\section{- To cite this version:}

Keyla Perez, Yvon Robert. Observaciones sobre estacionalidad de vuelos de áfidos cubanos y particularmente de Myzus persicae (Sulz.) en cultivo de patata. Agronomie, 1984, 4 (2), pp.161-169. hal-00884623

\section{HAL Id: hal-00884623 \\ https://hal.science/hal-00884623}

Submitted on 1 Jan 1984

HAL is a multi-disciplinary open access archive for the deposit and dissemination of scientific research documents, whether they are published or not. The documents may come from teaching and research institutions in France or abroad, or from public or private research centers.
L'archive ouverte pluridisciplinaire HAL, est destinée au dépôt et à la diffusion de documents scientifiques de niveau recherche, publiés ou non, émanant des établissements d'enseignement et de recherche français ou étrangers, des laboratoires publics ou privés. 


\title{
Observaciones sobre estacionalidad de vuelos de áfidos cubanos y particularmente de Myzus persicae (Sulz.) en cultivo de patata
}

\author{
Keyla PEREZ \& Yvon ROBERT (*) \\ Ministerio de la Agricultura, Estación experimental de papas y granos "Tomeguin », Carretera de Tumbadero, \\ Alquizar, Habana, Cuba. \\ (*) I.N.R.A., Laboratoire de Zoologie, Centre de Recherches de Rennes, BP 29, F 35650 Le Rheu (l)
}

La actividad de vuelo de los pulgones fue estudiada en Cuba durante 4 años en trampas amarillas funcionando todo cl año (trampas "permanentes») y durante el ciclo del cultivo de la patata (trampas « temporales»). A pesar de la existencia de una estación muy lluviosa de mayo a octubre, y de una estación "seca " de noviembre a abril, áfidos alados fueron capturados durante todo el año con 2 o 3 picos de capturas más importantes, con la excepción de Myzus persicae que presentó un vuclo «estacional » principalmente durante los meses más secos. Las temperaturas superiores a $30031^{\circ} \mathrm{C}$ parecicron impedir la actividad de vuelo de esta especic. Ninguna captura tampoco fue observada antes de enero cuando el período lluvioso se prolongó hasta el fin de noviembre ; al contrario cuando el período «seco » comenzó en octubre o antes, las capturas fueron precoces y abundantes continuando hasta abril.

La proporción de $M$. persicae en las capturas de trampas colocadas en los cultivos de la varicdad « Arka " fue siempre más grande que en la variedad « Désirée » pero no parece que esto depende de las fechas de siembra de las variedades. Esta proporción de las capturas en trampas «permanentes » es más reducida, pero a pesar de esto las capturas de esta especie en las diferentes trampas estan bien correlacionadas en 5 casos de 8 . Estos resultados son discutidos en el ámbito de un estudio cpidemiológico de las enfermedades viralcs de la patata transmitidas por pulgones.

Palabras claves adicionales : Zona tropical, trampas amarillas.

Observations sur l'activité saisonnière de vol de pucerons à Cuba et particulièrement de Myzus persicae (Sulz.) en culture de pomme de terre.

L'activité de vol des pucerons a étć étudiée à Cuba pendant 4 ans au moyen de pièges jaunes fonctionnant toute l'année (pièges «permanents") et pendant la durée du cycle de culture de la pomme de terre (pièges " temporaires "). Malgré l'existence d'une saison très pluvicuse de mai à octobre et d'une saison « sèche " de novembre à avril, des pucerons ailés ont été capturćs pendant toutc l'année avec 2 ou 3 pics de captures plus importantes, à l'exception de Myzus persicae qui a présentć un vol «saisonnier », principalement pendant les mois les plus secs. Des températures supéricures à 30 ou $31^{\circ} \mathrm{C}$ ont semblé empêcher l'activité de vol de cette espèce. Aucune capture n'a été non plus observée avant janvier lorsque la période pluvieuse s'est prolongée jusqu'à la fin de novembre ; au contraire, quand la période « sèche » a commencé en octobre ou avant, les captures ont été précoces et abondantes et elles se sont poursuivies jusqu'en avril.

La proportion de $M$. persicae dans les captures de pièges placés dans les cultures de la variété «Arka a toujours été plus grande que dans la variété « Désiréc », mais il ne semble pas que cela dépende des dates de plantation des variétés. Cette proportion dans les captures des pièges "permanents \# est plus faible mais les captures de cette espèce dans les différents pièges sont néanmoins bien corrélées dans 5 cas sur 8 .

Ces résultats sont discutés dans le cadre d'une étude épidémiologique des maladies à virus de la pomme de terre transmises par pucerons.

Mots clés additionnels : Zone tropicale, pièges jaunes. potato crops in Cuba.

The flight activity of aphids was studied in Cuba for 4 years by means of yellow traps operated all the year round ('permanent' traps) and during the potato season ('temporary' traps). In spite of the existence of a very 
rainy season from May to October and of a 'dry' scason from November to April, winged aphids were caught throughout the year with 2 or 3 peaks of more abundant catches. Only Myzus persicae showed 'seasonal' flight, mainly during the dryer months. Temperatures above 30 or $31{ }^{\circ} \mathrm{C}$ apparently prevented any flight activity by this species. No catch was observed before January if the rainy season persisted till the end of November ; however when the 'dry' period began in October or before, catches were early and abundant and continued till April.

The proportion of $M$. persicae caught in crops of varicty 'Arka' was always grcater than in variety 'Désirée' but did not seem to depend on the planting dates of the varieties. This proportion was lower in the catches by the 'permanent' traps but the catches of this species in the different traps were nevertheless well correlated in 5 cases out of 8 .

These results are discussed within the scope of an epidemiological study of aphid-borne potato virus discases.

Additional key words : Tropical zone, yellow traps.

\section{INTRODUCCIÓN}

En un número creciente de países situados en zona bioclimática tropical, el cultivo de la patata ha aumentado considerablemente sus superficies, no solamente para el consumo sino también para la multiplicación de scmillas importadas de países productores en climas templados. Generalmente esta multiplicación se efectua una o varias veces dependiendo del país y de la calidad de semilla que se quiera obtener.

Unos de los factores principales que limitan esta reproducción lo constituyen los pulgones que por ser vectores de numerosos virus los diseminan muy rápidamente y comprometen a término más o menos corto el estado sanitario del cultivo, que trae como consecuencia una baja en los rendimientos. La fuente de virosis puede ser a la vez «importada» y local, mientras que la producción de los pulgones es siempre local. El conocimiento de la fauna de los áfidos, de su biología y de sus características de vida constituyc un requisito mínimo para scleccionar las mejores estrategias de producción de plantas sanas. La fauna de los áfidos de Cuba es bien conocida hoy por los trabajos realizados por MülLER \& SEIDEL (1968) los cuales han reportado 27 especies y por HoLMAN (1974) señalando 83. Según MÜllek \& SEIDEL, algunas especics como Aphis craccivora Koch, Aphis gossypii Glover, Myzus persicae (Sulz.) son las más abundantes. Esta razón pucde buscarse en la polifagia de estas especies (por ejemplo Aphis citricola Van der Goot (=Aphis spiraecola Patch)).

Por desgracia, en el trópico, hasta ahora, se han realizado y publicado pocos trabajos sobre las características biológicas precisas y sobre la dinámica de las poblaciones de cada una de las diferentes especies de pulgones particularmente en la Amćrica del Sur y en las Islas de las Antillas, con excepción de los resultados publicados por MIGLIORI et al. (1977) en Guadalupe. Como indica WOLDA (1979) en sus investigaciones realizadas en Panamá, « las tcorías que existen sobre lé dinámica de las poblaciones de insectos y sobre sus fluctuaciones en abundancia, se fundan casi totalmente en estudios realizados en la zona templada «y ».. se debe tener mucho cuidado de no llegar a conclusiones generales basándose en datos que cubren solamente un año, en un sólo lugar y a un sólo grupo de insectos ». Estas afirmaciones pueden aplicarse perfectamente al caso de los áfidos : el ciclo biológico de los áfidos tropicales es anholocíclico por las condiciones climáticas que favorecen una reproduccion partenogenćtica permanente aunque cn cicrtas especies como $M$. persicae (BLACKMAN, 1974 ; HoLMAN, 1974), la posibilidad de una producción de machos puede ocurrir aun («androcíclia » según BLACKMAN, 1971). En estas condiciones, surge un problema muy importante para la agricultura que es de saber dónde, cómo y cuándo sc efectuan los cambios entre plantas hospedantes puesto que teoricamente la formación de individuos alados puede ser permanente. En clima templado húmedo donde las estaciones son bien definidas, se ha mostrado (ROBERT \& ROUZEJOUAN, 1976a) que la misma especie de áfido tiene la misma periodicidad de vuelo en cualquier tipo de ciclo a que pertenezcan sus cepas (anholocíclicas u holocíclicas) aunque los diferentes vuclos no sean compuestos de las mismas formas estacionales de pulgones especialmente en el verano (hembras partenogenéticas aladas anholocíclicas o hembras partenogenéticas aladas fundatrigenias holocíclicas) y en el otoño (hembras partogenéticas aladas anholocíclicas o ginóparas aladas y machos alados). En zonas tropicales, la temperatura y la duncación del día ticnen habitualmente poca variación durante cl año al contrario de las caídas de las lluvias que manifiestan una distribución estacional más o menos bien determinada desde situaciones con lluvia casi permanente (clima «no estacional "; Mc ELRAVY et al., 1981) hasta situaciones con alternancia de épocas lluviosas y secas (WOLDA, 1978). Eso trae como consecuencia posibilidades de fluctuaciones en el desarrollo de la flora en varios períodos del año (WOLDA, 1978) y probablemente igual para los áfidos en los nuevos retoños (EASTOP, 1961; DuVIARD \& POLleT, 1973). Ejemplos de esto fucron mostrados por EASTOP (1958) en Nigeria y por DUVIARD \& MERCADIER (1973) en la Costa de Marfil en cuya sabana $A$. gossypii, A. citricola, Pentalonia nigronervosa Coquerel y Tetraneura nigriabdominalis Sasaki presentan 2 picos principales en sus capturas en trampas amarillas, ocurriendo el primcro durante la época relativamente seca del período lluvioso de junio a septiembre y el scgundo durante la estación más seca entre noviembre y marzo; sin embargo, una actividad de vuelo puede siempre encontrarse durante el año aunque a veces reducida. Otro caso similar pucde extraerse de los datos de Migliori et al. (1977) en Guadalupe en la cual una de las zonas donde los pulgones estan los más abundantes en las trampas es la más seca y ticne temperaturas máximas supcriores a $30^{\circ} \mathrm{C}$ de abril a noviembre: $M$. persicae se captura principalmente entre noviembre y febrero (temperaturas máximas inferiores a $30^{\circ} \mathrm{C}$ ) a pesar de la presencia de cultivos de hortalizas durante un período más largo de ticmpo. En fin, en Brasil, DE Oliveira (1971) señala también que precipitaciones abundantes y temperaturas de más de $30^{\circ} \mathrm{C}$ reducen el número de alados recolectados. Al contrario, en Surinam, VAN HOOF (1962) señala que la actividad de vuelo conjunto de $A$. citricola y $A$. gossypii, de $P$. nigronervosa, de Toxoptera citricidus (Kirkaldy) tiene su máximo en diciembre y junio-julio cn los cuáles también incide el máximo de lluvia.

En Cuba, hace pocos años, se iniciaron trabajos de investigación en el campo de la epidemiología de las enfermedades virales con el fin de ayudar a una buena pro- 
ducción de semilla. Actualmente, el cultivo de patata se hace entre los meses de diciembre y abril con irrigación. Se mostró que la especie más encontrada en las hojas era M. persicae (PEREZ, 1980) la cual constituye por lo menos en el laboratorio el más eficiente agente vector de virus especialmente del virus no persistente $\mathrm{Y}$ y del virus persistente del enrollamiento de las hojas. Sin embargo en el campo los virus no persistentes también los pueden transmitir otras especies de áfidos que no se reproducen en la patata como se demostró en Europa entre los años 1974 y 1976 cuando un pulgón de los cereales, Rhopalosiphum padi L., por su abundancia aunque con capacidad vectriz baja se reveló como diseminador del virus Y (ROBERT, 1978). Por esta razón, investigaciones sobre la periodicidad de vuelo de diferentes especies de áfidos fueron conducidas entre 1977 y 1981.

En esta publicación se presentarán resultados de capturas de áfidos en trampas amarillas «permanentes » durante estos años así como «temporales» durante el ciclo del cultivo de la patata.

\section{MATERIAL Y MÉTODOS}

Este trabajo se efectuó en la « Estación experimental de papas y granos » situada en el municipio Alquizar a $40 \mathrm{~km}$ al Sur de la ciudad de la Habana $\left(22^{\circ} 48^{\prime}\right.$ lat. N., $82^{\circ} 35^{\prime}$ long. O., aproximadamente) en una región de cultivos de hortalizas irrigados en el surco o por aspersión. Esta estación, en la cual se siembran solamente cultivos de patatas, soja, maíz y frijoles regados, tiene alrededor de 40 ha en suelo ferralítico rojo. Cultivos de patatas están abundantes en los alrededores de la estación.

Se utilizaron trampas de $30 \times 30 \times 8 \mathrm{~cm}$ pintadas en su interior de amarillo "botón de oro" parecidas a las utilizadas en el oéste de Francia en cultivos de patata (ROBERT et al., 1974) rellenas con agua hasta $3 / 4$ de su volumen y algunas gotas de detergente para la mejor captura de los pulgones. Se colocaron 4 rampas « permanentes » a nivel del suelo en áreas de césped de algunas decenas de $\mathrm{m}^{2}$ sobre hierba bien cortada en puntos diferentes de la estación apartados unos de otros de algunas centenas de metros, a partir de la primera semana de junio 1977 hasta finales del mes de marzo 1980 , pero a partir de abril de este mismo año se continuó el trabajo con 3 de éstas solamente. Paralelamente, en áreas de cultivos experimentales de patatas, se colocaron 2 trampas similares, a nivel del suelo en el surco, dentro de una parcela de la variedad «Ar$\mathrm{ka}$ » y otra de « Désirée " de alrededor de 0,5 ha. La distancia entre éstas varió entre 20 y 40 metros. El período de captura se extendió desde finales de diciembre y principio de enero hasta finales de marzo dependiendo de la fecha de siembra durante los años 1978, 1979, 1980 y 1981. "Arka " fue sembrada el 19, 29, 28 y 12 de diciembre de 1977, 1978, 1979 y 1980 , «Désirée » el 5 y 6 de enero de 1978 y 1979 , y el 10 y 25 de diciembre de 1979 y 1980 . Cada cultivo fue regado por aspersión. Todos los insectos recolectados tres veces por semana fueron conservados en alcohol de $70^{\circ}$ y posteriormente identificados en el laboratorio.

Las temperaturas máximas y mínimas así como las precipitaciones fueron registradas por una estación meteorológica situada alrededor de $5 \mathrm{~km}$ de la estación.

Para realizar las comparaciones de las capturas de áfidos entre año, los datos fueron reagrupados por semanas «standard» (LEWIS \& TAYLOR, 1967) cuyas fechas de inicio de cada semana son constantes de un año a otro cuando se excluye del calendario los dias 29 de febrero y 31 de diciembre.

\section{RESULTADOS}

\section{A. Clima}

Cuba tiene un clima tropical húmedo (precipitaciones medias de 1200 a $1600 \mathrm{~mm}$ ) con 2 estaciones principales (fig. 1) : la primera muy lluviosa (más de $100 \mathrm{~mm}$ por mes), se extiende de mayo a octubre, presentando un período menos lluvioso en julio y agosto, la segunda es una estación relativamente seca con algo de lluvia. Las temperaturas medias mensuales fluctúan entre $21,7^{\circ} \mathrm{C}$, en enero y $27,2^{\circ} \mathrm{C}$ en agosto, las máximas son de $26,1^{\circ} \mathrm{C}$ en enero y $31,5^{\circ} \mathrm{C}$ en agosto, las mínimas de $18,2^{\circ} \mathrm{C}$ en febrero y $23,6^{\circ} \mathrm{C}$ en agosto. La duración del día tiene poca variación entre 10,8 horas en diciembre y 13,5 horas en junio.

En la provincia de la Habana donde se efectuaron las observaciones, las características climáticas fueron muy fluctuantes entre 1977 y 1981 (fig. 2). El período más lluvioso se detuvo en los meses de septiembre 1977 , diciembre 1978, octubre 1979 y diciembre 1980. La estación «seca » presentó también diferencias : por ejemplo, entre diciembre y marzo $1978,1979,1980,1981$, la cantidad de lluvia fue de $343,113,260,142 \mathrm{~mm}$ respectivamente pero más o menos bien distribuída entre estos meses. Es de notar que la mayor parte de los $260 \mathrm{~mm}$ en 1980 provienen de una caída de lluvia muy abundante de $116 \mathrm{~mm}$ durante la semana 8 (entre el 19 y 25 de febrero) lo que es excepcional en la estación seca (fig. 3 ).

\section{B. Fluctuaciones en las capturas de áfidos}

\section{Trampas "permanentes"}

\section{a) Especies capturadas}

Más de 20 especies fueron capturadas en las trampas: Aphis amaranthi Holman, A. citricola, Aphis coreopsidis (Thom.), A. craccivora, A. gossypii, Aphis nerii (B.D.F.), Capitophorus carduinus (Wlk), Carolinaia sp., Geopemphigus floccosus (Moreira), Hyperomyzus lactucae (L.), Hyste-

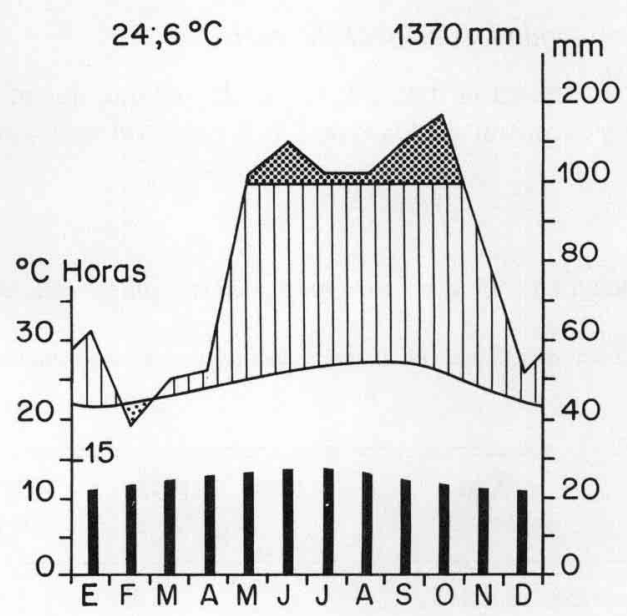

Figura 1

Diagrama climático de Cuba (promedio de 55 años) e histogramas de los promedios mensuales de la duración del día.

en punteado oscuro : periodo más lluvioso,

a rayas: periodo húmedo,

en punteado claro: periodo seco.

Diagramme climatique de Cuba (moyenne de 55 ans) et histogrammes des moyennes mensuelles de durée du jour.

en pointillés sombres : période très pluvieuse,

en hachures: période humide,

en pointillés clairs : période sèche. 


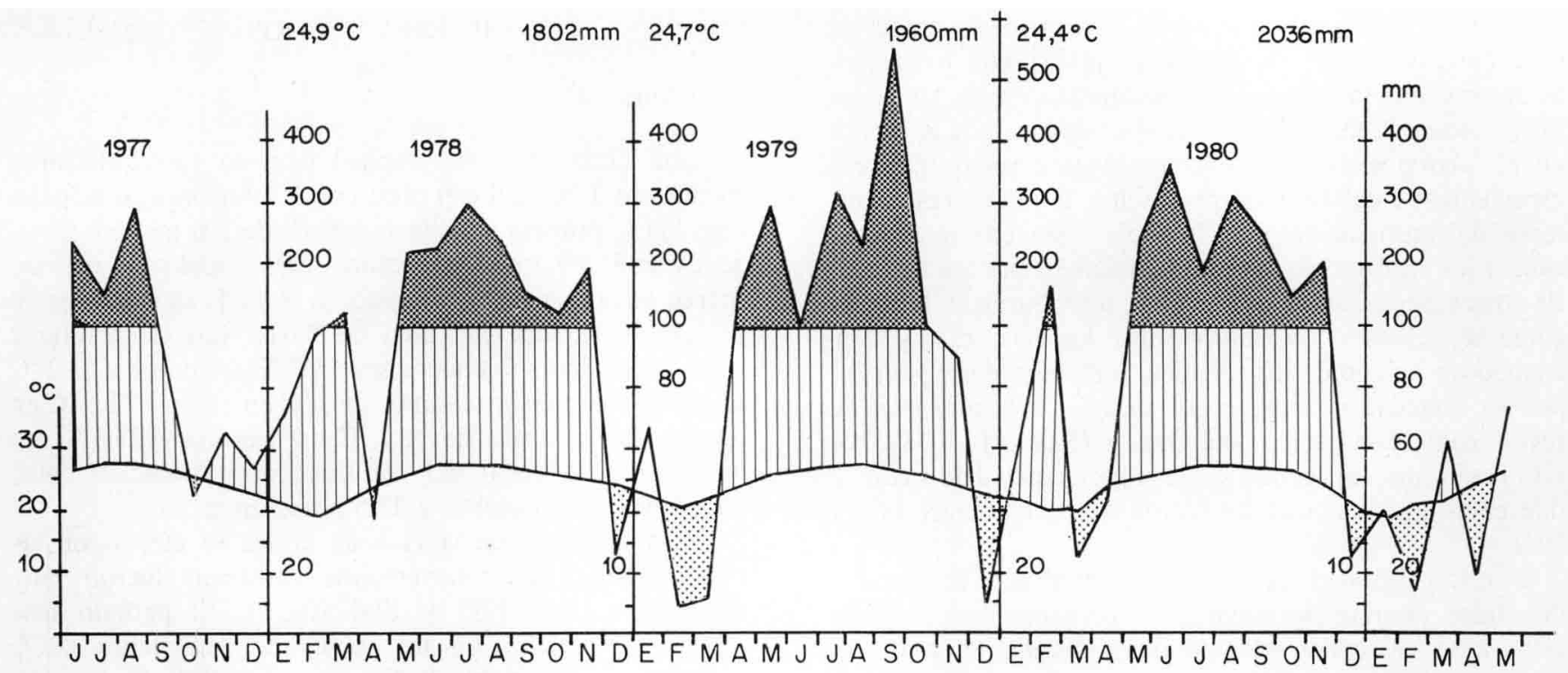

Figura 2

Diagrama climático anual de la zona al sur de la Habana donde se realizaron las investigaciones desde junio 1977 hasta mayo 1981.

roneura setariae (Thom.), Idiopterus nephrelepidis Davis, Lipaphis erysimi (Kltb), M. persicae, P. nigronervosa, Rhodobium porosum (Sanderson), Rhopalosiphum maidis (Fitch), R. padi, Rhopalosiphum rufiabdominalis (Sasaki), Schizaphis graminum (Rond.), Sipha flava Forbes, $T$. nigriabdominalis, Toxoptera aurantii (B.D.F.), Uroleucon sp.. Estas especies son las mismas que las capturadas en Guadalupe o casi (MiGLIORI et al., 1977).

Cinco especies son regularmente capturadas en cantidades mayores con relación a las otras, $M$. persicae, $A$. citricola, A. gossypii, A. craccivora y $T$. nigriabdominalis cuyos números totales representan cada año alrededor de 80 a 90 p. 100 del total capturado (cuadro 1). Es por esta razón que la continuación de este análisis se referirá solamente a ellas y precisarnente a las tres primeras.

\section{b) Actividad estacional de vuelo}

Como lo indica la figura 3 , se puede ver que durante todo el año se capturan áfidos con 2 o 3 picos de actividad más
Diagramme climatique annuel de la région du Sud de la Havane où ont été conduites les recherches de juin 1977 à mai 1981.

importante que ocurren a finales de octubre $(1977,1979$, $1980)$, encro $(1980,1981)$ febrero y marzo $(1978,1979$, $1980)$ y mayo $(1979,1980)$ o sea, principalmente, durantc la época «seca». A. citricola, A. gossypii, A. craccivora y T. nigriabdominalis aparecen como especies casi « no estacionales » aunque el porcentaje de las capturas de cada una de ellas tiene variaciones en sus fluctuaciones a lo largo del año. El cuadro 1 indica las diferencias en la estructura demográfica de la áfidofauna alada entre 2 períodos: cl primero se extiende de la semana 17 a la 48 y el segundo de la 49 a la 16 (época del cultivo de la patata). Los porcentajes relativos de capturas de $A$. gossypii están más grandes en la primera y los de $A$. citricola y $A$. craccivora en la segunda.

No se puede decir lo mismo de $M$. persicae pues tiene su actividad de vuelo solamente en el período "seco" con algunas variaciones entre años en lo referente a su duración y a su amplitud. La captura de esta especie fue a partir de octubre hasta abril de los años 1977-1978 y 1979-1980 mientras que en otros años sus capturas comienzan en enero 1979 y febrero 1981 con la excepción de un solo individuo

\section{CUADRO 1}

Composición específica, en porcentaje, de las capturas estacionales de áfidos por 4 trampas amarillas " permanentes " de 1977 a marzo 1980 y por 3, de abril 1980 a 1981.

Composition spécifique, en p. cent, des captures saisonnières de pucerons dans 4 pièges jaunes "permanents » de 1977 à mars 1980 et dans 3 , d'avril 1980 à 1981.

\begin{tabular}{|c|c|c|c|c|c|c|c|c|}
\hline $\begin{array}{c}\text { Año } \\
\text { Semana }\end{array}$ & $\begin{array}{c}1977 \\
22-48\end{array}$ & $\begin{array}{c}1977-78 \\
49-16\end{array}$ & $\begin{array}{r}1978 \\
17-48\end{array}$ & $\begin{array}{c}1978-79 \\
49-16\end{array}$ & $\begin{array}{c}1979 \\
17-48\end{array}$ & $\begin{array}{c}1979-80 \\
49-16\end{array}$ & $\begin{array}{r}1980 \\
17-48\end{array}$ & $\begin{array}{c}1980-81 \\
49-16\end{array}$ \\
\hline Myzus persicae (Sulzer) & 4,49 & 19,42 & 0 & 26,38 & 3,11 & 13,16 & 0 & 4,63 \\
\hline $\begin{array}{l}\text { Aphis citricola } \\
\text { Van der Goot }\end{array}$ & 35,76 & 47,83 & 22,90 & 34,97 & 26,64 & 34,82 & 50,96 & 32,90 \\
\hline Aphis gossypii Glover & 44,66 & 18,95 & 56,36 & 17,00 & 45,67 & 32,67 & 28,08 & 23,48 \\
\hline Aphis craccivora Koch & 1,21 & 2,99 & 2,18 & 11,04 & 1,21 & 10,73 & 3,73 & 7,34 \\
\hline $\begin{array}{l}\text { Tetraneura } \\
\text { nigriabdominalis Sasaki }\end{array}$ & 3,18 & 1,39 & 1,81 & 3,94 & 3,46 & 2,33 & 1,47 & 13,73 \\
\hline Otras especies & 10,70 & 9,42 & 16,75 & 6,67 & 19,90 & 6,29 & 15,76 & 17,92 \\
\hline Total & 1068 & 1936 & 275 & 1141 & 578 & 1071 & 883 & 626 \\
\hline
\end{tabular}



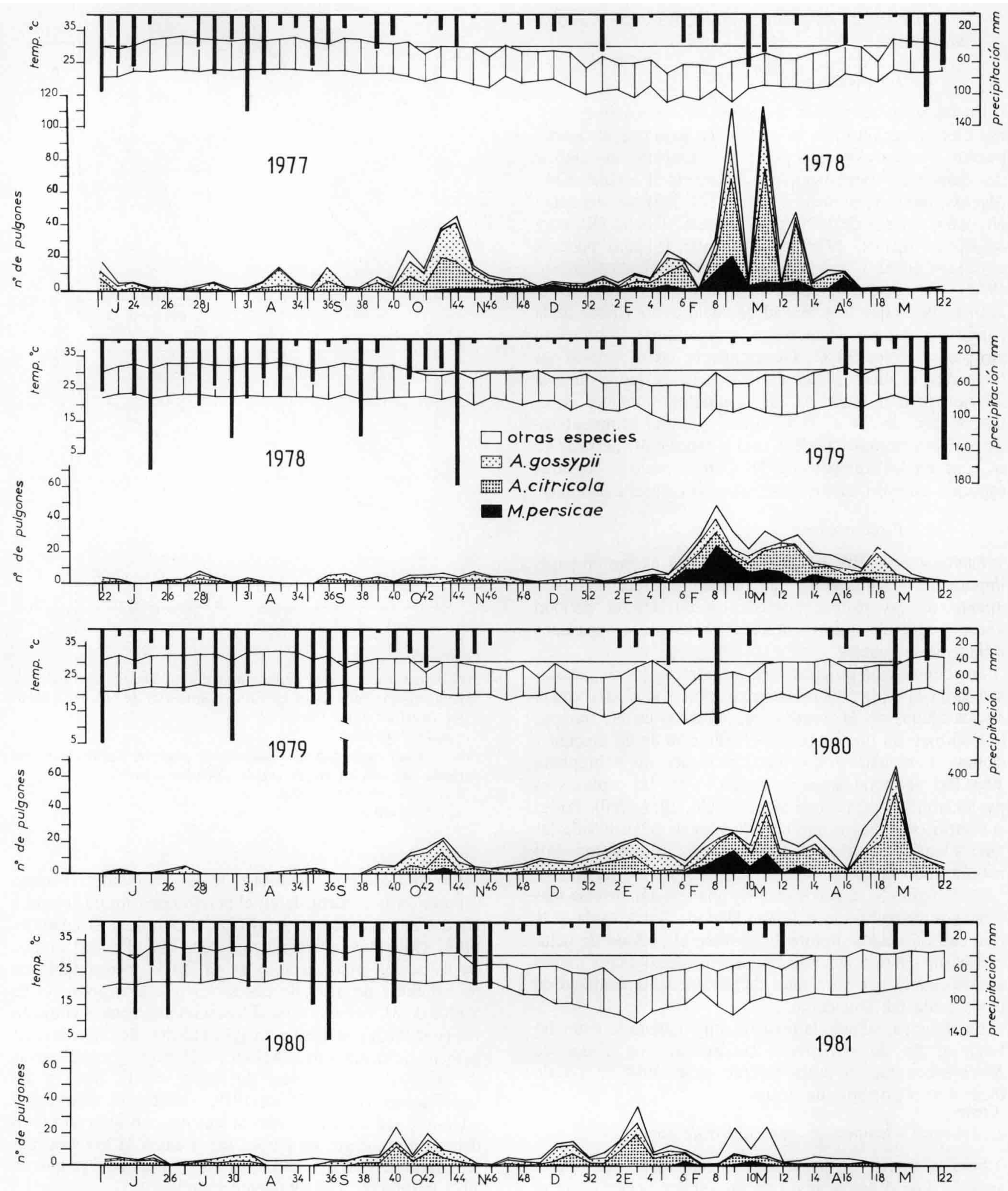

Figura 3

Variación de las capturas semanales, (promedio por una trampa amarilla) de alados de Myzus persicac, Aphis citricola, Aphis gossypii y total de especies, así como de las precipitaciones y temperaturas minimas y máximas de junio 1977 a mayo 1981.

encontrado en la semana 50 de 1980 . Su amplitud varía como se puede ver en la figura 3 , siendo menor de octubre hasta enero y mayor de enero a abril. El número total de
Variation des captures hebdomadaires (moyenne pour un piège jaune) d'ailés de Myzus persicae, Aphis citricola, Aphis gossypii et du total des espèces ainsi que des précipitations et températures minimales et maximales de juin 1977 à mai 1981.

alados de esta especie capturados en 4 trampas durante los 4 etapas fue de $424,310,220,37$, mostrando así diferencias notables entre éstas. 
c) Influencia de los factores climáticos sobre el vuelo de M. persicae

\section{a) Temperatura}

En las zonas templadas, las temperaturas máximas diurnas ejercen acción sobre la posibilidad para que los alados puedan levantar el vuelo a partir de la temperatura - umbral de despegue: por ejemplo, Aulacorthum solani Kltb, Macrosiphum euphorbiae Thom. y $M$. persicae nccesitan alrededor de más de $15^{\circ} \mathrm{C}$ para levantar el vuelo (RoBERT \& RouZE-JOUAN, 1978) mientras que $R$. padi necesita alrededor de $11^{\circ} \mathrm{C}$ solamente (ROBERT \& ROUZE-JOUAN, 1976b). Se observó también en 1976 (ROBERT \& RouzEJouAN, 1978) que la actividad de vuelo de los áfidos de la patata se detiene cuando las temperaturas sobrepasan alrededor de $\operatorname{los} 30^{\circ} \mathrm{C}$. Generalmente en el trópico las temperaturas diurnas nunca son más bajas que el umbral inferior pero a tenor de los resultados obtenidos aquí, parece que de 30 a $31^{\circ} \mathrm{C}$ constituye una temperaturaumbral superior encima de la cual la especic $M$. persicae no se coge en las trampas (fig. 3). Con respecto a las otras especies, parecen admitir temperaturas-umbral más altas.

\section{B) Precipitaciones}

La frecuencia e intensidad de las lluvias juegan un papel importante y múltiple ya que pueden favorecer el crecimiento de las plantas hospedantes durante el período « seco » o por el contrario, ocasionar la muerte de los alados e impedir sus vuelos.

La acumulación progresiva de los porcentajes de cantidades de lluvia caída cada mes entre octubre y abril así como la de los alados de $M$. persicae recolectados en las trampas (fig. 4) muestra que cuando la distribución de las precipitaciones es regular y que sus cantidades no sobrepasan 50 p. 100 del total antes de enero, la de las capturas es parecida (1977-1978 y con menor título, 1979-1980). Por el contrario, se observa que cuando más de 50 p. 100 de las lluvias han caído ya antes de diciembre, no se captura casi ningún áfido antes de enero (1978-1979 y 1980-1981).

De la figura 5 , se puede deducir una relación inversa más o menos estrecha entre la cantidad de lluvia caída y la cantidad de alados capturados durante el período de octubre hasta enero: precisamente se recolectó tanto menos alados cuanto que ya a fines de noviembre la cantidad de lluvia caída fue abundante.

En resumen, cuando la estación muy lluviosa se cxtendió hasta el fin de noviembre, las capturas de alados de $M$. persicae fueron practicamente nulas hasta el fin de diciembre o principio de enero.

\section{Trampas "temporales" en cultivo de patata}

Sólo la especie $M$. persicae se tomará en cuenta en este análisis. Los datos relativos de las otras especies serán el objeto de estudio cl cual se publicará posteriormente.

a) Comparación de las capturas de M. persicae con relación al número total de pulgones capturados en cultivo de "Arka " $y$ "Désirée "

El cuadro 2 indica que las capturas totales de pulgones son siempre más elevadas en las trampas situadas en la variedad "Arka» que en las situadas en la variedad «Désirée » con la excepción en 1980 en la variedad «Désirée " que fue sembrada 18 días antes que la variedad "Arka » (10 de diciembre 1979 contra 28 de diciembre). Sin embargo, este mismo año, la proporción de alados de M. persicae es igualmente más elevada en «Arka ».
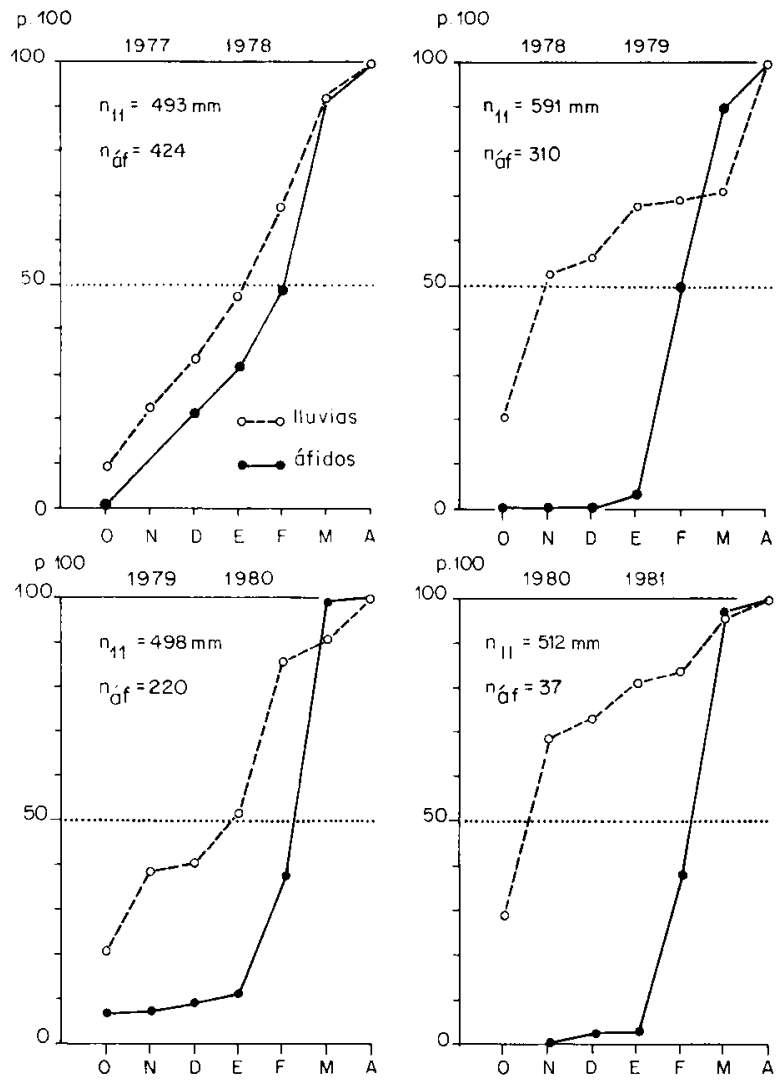

Figura 4

Porcentajes acumulativos de las cantitades de lluvias y de alados de Myzus persicae capturados en trampas amarillas de octubre a abril. $n_{1 l}:$ total de lluvia $(\mathrm{mm})$.

$n_{\text {af }}^{\prime}$ : total de alados.

Pourcentages cumulatifs des quantités de pluies et d'ailés de Myzus persicac capturés en pièges jaunes d'octobre à avril:

$n_{l 1}:$ total des pluies $(\mathrm{mm})$.

$n_{a f}^{\prime}:$ total d'ailés.

La comparación estadística de las cantidades relativas capturadas fuc efectuada en el período de captura común a las dos situaciones con la ayuda del criterium 2î (ARBONNIER, 1966) cuyo empleo es más facil que el del $\chi^{2}$ aunque de capacidad equivalente y se utiliza la misma tabla de probabilidad de éste. Se puede ver que la proporción de alados de $M$. persicae tiene diferencias altamente significativas $(\mathrm{p}<0,001)$ en 1980 y en 1981 (13 días de diferencia en la fecha de siembra de «Arka " y «Désirée ») significativas $(\mathrm{p}<0,05)$ en 1978 (con diferencia de 17 días) y no significativas $(p>0,05)$ en 1979, año donde «Arka» $y$ «Désiréc » fueron plantadas solamente con intervalo de 8 dias ; sin embargo, no parece ser la causa la siembra más temprana de «Arka » con respecto a «Désirée » ya que en 1980 la diferencia es altamente significativa.

Las trampas colocadas en cultivo de variedad "Arka " capturan proporcionalmente más $M$. persicae que en la variedad «Désirée ».

b) Comparación de las capturas de M. persicae en trampas "permanentes " y en trampas «temporales"

Con excepción de 1978, las trampas situadas en un cultivo de patata capturan un número total de áfidos poco diferente del que se captura en las trampas «permanentes» (cuadro 2).

En lo que concierne a $M$. persicae, se pueden hacer dos observaciones :

- el porcentaje de alados de esta especie con relación al 


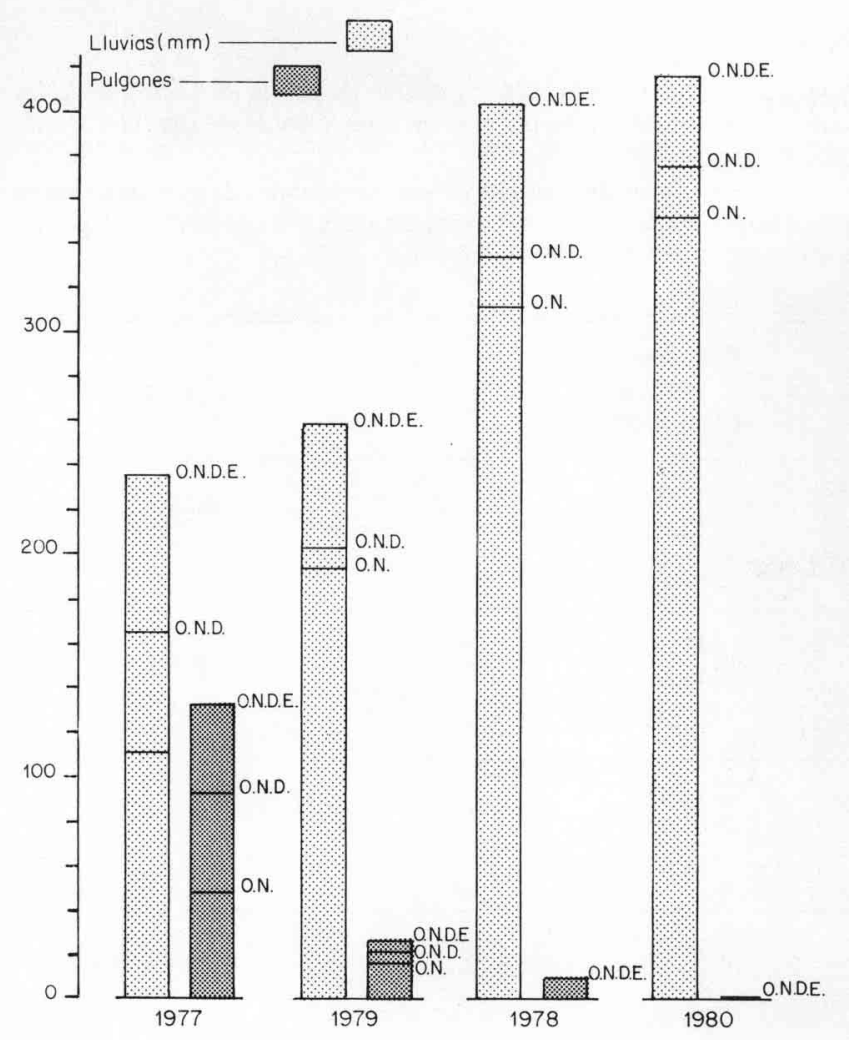

Figura 5

Total de lluvia caida durante los meses de octubre y noviembre (O.N.), octubre, noviembre y diciembre (O.N.D.), octubre, noviembre, diciembre y enero (O.N.D.E.) (histogramas izquierdos) $y$ total de alados de Myzus persicae capturados en 4 trampas amarillas durante los mismos periodos (histogramas derechos).

Total des pluies tombées pendant les mois d'octobre et novembre (O.N.), octobre, novembre et décembre (O.N.D.), octobre, novembre, décembre et janvier (O.N.D.E.) (histogrammes de gauche) et total d'ailés de Myzus persicae capturés dans 4 pièges jaunes pendant les mêmes périodes (histogrammes de droite).

total capturado es siempre mucho más elevado en las trampas «temporales», donde constituye más de 30 p. 100 del total $(32,02$ p. 100 a 59,22 p. 100$)$ que en las trampas « permanentes » $(6,44$ p. 100 a 28,82 p. 100) (cuadro 2).

Parece que la proporción de alados de $M$. persicae que vuelan por encima del cultivo de patata es más elevada que aquellos presentes por encima del césped si se admite que una trampa amarilla proporciona datos cuantitativos, o bien que la atracción relativa de las trampas por $M$. persicae es más fuerte cuando éstas son colocadas en una parcela de patatas, sobre el suelo yermo.

- después de la transformación en $\log (\mathrm{n}+1)$, la comparación de las cantidades de alados de $M$. persicae capturados semana por semana en las trampas «permanentes $"$ y de aquellas observadas por una parte en las colocadas en la variedad «Arka" y por otra parte en la variedad «Désirée » (cuadro 3) muestra que estadísticamente estas cantidades están muy fuertemente correlacionadas en 1979 y en $1980(p<0,01)$ y no lo están en $1981(p>0,10)$. En 1978, están fuertementc correlacionadas en el caso de «Arka »/trampas «permanentes» $(\mathrm{p}<0,02)$ sólo. En cl caso de «Désirée »/trampas «permanentes », la correlación no está significativa aunque el valor de $r(0,562)$ está próximo al valor de la tabla del coeficiente de correlación ( $r=0,576$ con probabilidad $p=0.05$ ).

Es necesario señalar que en 1979 y en 1980, las capturas efectuadas en «Arka " y en «Désirée " han proporcionado resultados parecidos con relación a las trampas « permanen- tes $\gg:$ los coeficientes de correlación así como las inclinaciones de las rectas son idénticos; por otra parte, ninguna de éstas difiere estadísticamente de l. Sin embargo, existen diferencias entre las situaciones y entre años en las proporciones en las capturas de trampas « temporales » $\mathrm{y}$ « permanentes $»$ ya que los valores de $« b$ » de las ecuaciones de regresión de tipo $\mathrm{Y}=\mathrm{a} \mathrm{X}+\mathrm{b}$ no son los mismos: son siempre mayor en el caso de « Arka "/trampas «permanentes » que en el caso de «Désirée »/trampas «permanentes». Así en 1979 y 1980, las trampas en «Arka " han capturado 1,8 veces más de $M$. persicae que las en « Désirée ».

En conclusión, se puede deducir que la eficacia de captura de trampas en "Arka» es superior de aquellas situadas en «Désirée » con respecto a las «permanentes» en lo que concierne a $M$. persicae. Además las proporciones entre las capturas efectuadas en los tres casos no tienen muchas variaciones a lo largo del tiempo, lo que puede indicar cierta fiabilidad y fidelidad en este sistema de captura.

\section{DISCUSIÓN Y CONCLUSIÓN}

Este trabajo aporta una contribución al conocimiento de la actividad de vuclo de los pulgones en medio tropical. Por nuestro conocimiento, es la primera vez que este estudio se efectúa durante un período tan largo (4 años).

A pesar de las diferencias climáticas observadas durante estos 4 años, un cierto número de hechos constantes pueden ser señalados :

- cinco especies sobre más de 20 capturadas por las trampas constituyen sólo el 80 a 90 p. 100 de los efectivos con una fuerte predominancia de tres de ellas, A. citricola, $A$. gossypii y $M$. persicae. Tal predominancia de ciertas especies fue señalada por MIGLIORI et al. (1977) en Guadalupe y por DUVIARD \& MERCADIER (1973) en África (A. gossypii, A. citricola, Schoutedenia lutea Van der Goot). Como apuntan algunos autores, la abundancia de sus capturas puede ser debida a una cierta selectividad de la trampa amarilla con respecto a los pulgones (EASTOP, 1955, 1957, O'LOUGHLIN, 1963) pero como indican DuVIARD \& MERCADIER (1973) ellas corresponden sin embargo a una abundancia efectiva de los alados a un período dado y a una actividad importante de vuclo.

- $M$. persicae aparece como una especic "estacional» cuya actividad de vuelo se sitúa durante la estación « seca » mientras que otras especies como $A$. citricola y $A$. gossypii son capturadas durante todo el año. Es difícil de definir las razones de esta periodicidad pues un estudio cuantitativo de la producción anual de alados de $M$. persicae en diversas plantas hospedantes no fue efectuada durante este período de estudio, salvo sobre la patata (PEREZ, 1980 y en preparación): el análisis demográfico de las poblaciones ápteras de $M$. persicae sobre esta planta de enero a marzo muestra una buena coincidencia temporal entre la producción de ninfas (larvas de alados) y la captura de alados.

Netamente aparece una influencia de la temperatura y del régimen de precipitaciones sobre el carácter estacional del vuelo de $M$. persicae. Aunque sca difícil de afirmar que las temperaturas superiores a 30 o $31^{\circ} \mathrm{C}$ reducen o impiden la actividad de vuelo sobre la base de los datos semanales (O’LOUGHLIN, 1963), parece que estas temperaturas juegan un papel de umbral superior para la actividad de vuclo de esta especie : si tal es el caso, es asombroso que este pulgón surgido de la parte templada del viejo Mundo y capaz por otra parte de adaptarse biologicamente (BLACKMAN, 1974) 


\section{CUADRO 2}

Número total de pulgones capturados en 1978, 1979, 1980, 1981 en 4 trampas "temporales " colocadas en cultivo de patata en cada una de las variedades "Arka " $y$ " Désirée " y en 4 trampas "permanentes"; porcentajes de alados de Myzus persicae en estas y grado de significación de las diferencias observadas en las capturas relativas de esta especie.

Nombre total de pucerons capturés en 1978, 1979, 1980, 1981 dans 4 pièges "temporaires » situés dans une culture de pommes de terre de chacune des variétés «Arka "et «Désirée » et dans 4 pièges "permanents»; pourcentages d'ailés de Myzus pcrsicae dans ces captures et degré de signification des différences observées dans les captures relatives de cette espèce.

\begin{tabular}{|c|c|c|c|c|c|}
\hline $\begin{array}{l}\text { Año y } \\
\text { Semana }\end{array}$ & Situación & $\begin{array}{l}\text { Total áfidos } \\
\text { capturados }\end{array}$ & $\begin{array}{l}\text { Por ciento } \\
M . \text { persicae } \\
\text { en el total }\end{array}$ & $2 \hat{I}\left({ }^{a}\right)$ & $\mathrm{p}$ \\
\hline 1978 & $\begin{array}{l}\text { "Arka» } \\
\text { "Désirée" }\end{array}$ & $\begin{array}{l}876 \\
712\end{array}$ & $\begin{array}{l}37,90 \\
32,02\end{array}$ & 5,963 & $0,01<p<0,05$ \\
\hline 2 à 13 & «permanente» & 1688 & 16,35 & & \\
\hline 1979 & $\begin{array}{l}\text { "Arka» } \\
\text { "Désirée" }\end{array}$ & $\begin{array}{l}1798 \\
1180\end{array}$ & $\begin{array}{l}43,60 \\
40,85\end{array}$ & 2,218 & $p>0,05$ \\
\hline 3 à 14 & "permanente» & 1013 & 28,82 & & N.S. \\
\hline 1980 & $\begin{array}{l}\text { "Arka» } \\
\text { "Désirée" }\end{array}$ & $\begin{array}{l}1018 \\
1058\end{array}$ & $\begin{array}{l}59,92 \\
49,99\end{array}$ & 46,544 & $\mathrm{p}<0,001$ \\
\hline 2 à 13 & «permanente» & 1056 & 18,65 & & \\
\hline 1981 & $\begin{array}{l}\text { "Arka» } \\
\text { "Désirée" }\end{array}$ & $\begin{array}{l}556 \\
509\end{array}$ & $\begin{array}{l}44,96 \\
33,59\end{array}$ & 14,428 & $\mathrm{p}<0,001$ \\
\hline 3 à 12 & «permanente» & 528 & 6,44 & & \\
\hline
\end{tabular}

$\left({ }^{a}\right) x_{0,05 ; 1}^{2}=3,841$.

\section{CUADRO 3}

Correlación entre las capturas semanales de Myzus persicae en las trampas "temporales situadas en cultivo de patata variedad «Arka " $y$ trampas "permanentes", por una parte, y en variedad "Dćsirćc " y trampas " permanentes ", por otra parte. $n=$ número de pares $; r=$ coeficiente de correlación $; p=$ probabilidad.

Corrélation entre les captures hebdomadaires de Myzus persicac dans les pièges "temporaires" situés en culture de pomme de terre variété "Arka» et dans les pièges "permanents», d'une part, variété «Désirćc » el pièges "permanents", d'autre part. $n=$ nombre de couples $; r=$ coefficient de corrélation $; p=$ probabilité.

\begin{tabular}{|c|c|c|c|c|c|c|c|}
\hline \multicolumn{4}{|c|}{ Arka «permanente» } & \multicolumn{4}{|c|}{ Désirée « permanente" } \\
\hline $\begin{array}{l}\text { Ecuación de la regresión } \\
\quad(\text { en } \log (n+1))\end{array}$ & $\mathrm{n}$ & $r$ & $\mathrm{p}$ & $\begin{array}{l}\text { Ecuación de la regresión } \\
\quad(\text { en } \log (n+1))\end{array}$ & $\mathrm{n}$ & $r$ & $\mathrm{p}$ \\
\hline & & & 1978 & & & & \\
\hline $\mathrm{Y}=1,2571 \mathrm{X}-0,4185$ & 12 & 0,659 & $\mathrm{p}<0,02$ & $\mathrm{Y}=0,8560 \mathrm{X}-0,0284$ & 12 & 0,562 & $\begin{array}{c}0,10<p<0,05 \\
\text { N.S. }\end{array}$ \\
\hline$Y=0,9905 X+0,3951$ & 12 & 0,855 & $\mathrm{p}<0,01{ }_{1980}^{1979}$ & $Y=0,9851 X+0,1394$ & 13 & 0,872 & $\mathrm{p}<0,01$ \\
\hline$Y=0,7884 X+0,6884$ & 13 & 0,771 & $\mathrm{p}<0,01$ & $Y=0,7818 X+0,4270$ & 13 & 0,687 & $\mathrm{p}<0,01$ \\
\hline$Y=0,6959 X+0,8766$ & 10 & 0,547 & $\begin{array}{l}p>0,10 \\
\text { N.S. }\end{array}$ & $Y=0,3326 X+0,9535$ & 12 & 0,313 & $\begin{array}{c}p>0,10 \\
\text { N.S. }\end{array}$ \\
\hline
\end{tabular}

no se adapte mejor a las temperaturas elevadas del clima tropical. El papel posible de las precipitaciones y de los períodos durante los cuales ellas se producen ya fue señalado por EASTOP $(1957,1958)$, DuviaRd \& POLLET (1973), WOLDA $(1978,1979)$ así como los resultados obtenidos durante los 4 años de captura lo confirman aportando elementos suplementarios. Parece que la continuación de la estación muy lluviosa hasta el fin de novicmbre podría retardar el inicio de los vuelos de $M$. persicae hasta enero: esto podría ser una indicación interesante para adaptar las fechas de plantación de patata con el fin de evitar la diseminación de virus.

- la comparación de una misma técnica de capturas en 3 situaciones (trampas «temporales" en cultivo de "Arka » y de «Désirée », trampas «permanentes» sobre cćsped) proporcionaba resultados comparables en los casos en lo que concierne $M$. persicae: primero las capturas relativas fueron significativamente correlacionadas en 
5 casos de 8 lo que muestra una cierta fiabilidad del sistema de captura por trampas amarillas y luego las relaciones entre éstas en las 3 situaciones presentan una cierta constancia a lo largo del tiempo, lo que significa una cierta fidelidad en las respuestas aunque en caso de «Arka » $\mathrm{y}$ « Désirée » las condiciones inmediatas alrededor de las trampas varían en función del crecimiento de las plantas mientras que en las «permanentes» varían poco (hierba regularmente cortada). COSTA (1972) ha mostrado el papel repelente del césped respecto al suelo yermo.

Esto nos permite pensar que en el futuro, será posible reducir o suprimir el empleo de trampas amarillas en el cultivo de patata y conservar sólo las «permanentes », de utilización más facil cuya repartición geográfica podria ser extendida con vistas a crear una red de previsión de riesgo ocasionado por $M$. persicae y posiblemente por otros pulgones.

Queda un cierto número de trabajos a realizar, otros ya han comenzado para precisar la utilización óptima de estas trampas (altura de trampas, dimensión, substrato...) y su importancia exacta en el estudio de la dinámica de poblaciones de pulgones y de epidemiologia de las enfermedades virales de la patata.

Reçu le 9 janvier 1983. Accepté le 16 septembre 1983.

\section{AGRADECEMIENTO}

Agradecemos la colaboración directa en la realización de este trabajo a la auxiliar técnica Noelia Figueredo de la Estación experimental de papas y granos, a los Ingenieros de esta misma Estación por permitirnos utilizar las áreas experimentales de patatas, a los profesores G. Remaudière del Instituto Pasteur de Paris y F. LECLANT de la Escuela Nacional Superior de Agronomía de Montpellier (E.N.S.A.M.) por su ayuda prestada en el reconocimiento de algunas de las especies de pulgones, así como a Joëlle Rouze-Jouan y Evelyne TuRPEAu, técnicas del laboratorio de Zoología, Le Rheu.

\section{BIBLIOGRAFÍA}

Arbonnier P., 1966. L'analyse de l'information. Aperçu théorique et application à la loi multinomiale. Ann. Sci. For., 23, 951-1020. Blackman R.L., 1971. Variation in the photoperiodic response within natural populations of Myzus persicae (Sulz.). Bull. Entomol. Res., 60, 533-546.

Blackman R.L., 1974. Life cycle variation of Myzus persicae (Sulz.) (Hom. Aphididae) in different parts of the world, in relation to genotype and environment. Bull. Entomol. Res., 63, 595-607.

Costa C.L., 1972. Controle de molestias de virus de plantas con superficies reflectivas repelentes ao vector. Rev. Peru. Entomol., 15/1, 135-139.

De Oliveira A.M., 1971. Observações sôbre a influência de factôres climáticos nos populaçoes de afídeos em batata. Pesq. Agropec. Bras., Sér. Agron., 6, 163-172.

Duviard D., Mercadier G., 1973. Les invasions saisonnières de pucerons en culture cotonnière: origine et mécanismes. Coton Fibres Trop., 28 (4), 483-491.

Duviard D., Pollet A., 1973. Spatial and seasonal distribution of Diptera, Homoptera and Hymenoptera in a moist shrub savanna. Oikos, 24, 42-57.

Eastop V.F., 1955. Selection of aphid species by different kinds of insect traps. Nature, 176, 936.

Eastop V.F., 1957. The periodicity of aphid flight in East Africa. Bull. Entomol. Res., 48, 305-310.

Eastop V.F., 1958. Flight periodicity of some aphids and psyllids in Nigeria. Entomol. Month. Mag., 94, 32-33.

Eastop V.F., 1961. A study of the Aphididae (Homoptera) of West Africa. H.M.S.O. London, $93 \mathrm{p}$.

Holman J., 1974. Los áfidos de Cuba. Instituto cubano del libro, La Habana, 304 p.

Hoof H.A. Van, 1962. Observations on aphid flights in Surinam. Entomol. Exp. Appl., 5, 239-243.

Lewis T., Taylor L.R., 1967. Introduction to experimental ecology. Academic Press, London and New York, $401 \mathrm{p}$.

Mc Elravy E.P., Resh V.H., Wolda H., Flint Jr O.S., 1981. Diversity of adult Trichoptera in a "non-seasonal " tropical environment. Proc. 3rd Int. Symp. on Trichoptera, Dr W. Junk Publish. The Hague, vol. 20, 149-156.

Migliori A., Quiot J.B., Leclant F., Marchoux G., Coleno A., 1977. Premières observations sur l'épidémiologie du virus de la mosaïque du concombre et du virus de la mosaique de la pastèque en Guadeloupe. Ann. Phytopathol., 9 (2), 123-139.

Müller F.P., Seidel M., 1968. Beiträge zur Kenntnis der Blattlausfauna von Kuba (Homoptera $=$ Aphidina). Wiss. Z. Univ. Rostock, $17,439-448$.

O'Loughlin G.T., 1963. Aphid trapping in Victoria. I. The seasonal occurrence of aphids in three localities and a comparison of two trapping methods. Aust. J. Agric. Res., 14, 61-69.

Perez K., 1980. Datos preliminares sobre la dinámica poblacional de los áfidos en el cultivo de la papa (Solanum tuberosum) en diferentes localidades del país durante la campaña 1978-1979. Agrotec. Cuba, 12 (2), 37-45.

Robert Y., 1978. Rôle épidémiologique probable d'espèces de pucerons autres que celles de la pomme de terre dans la dissémination intempestive du virus $\mathrm{Y}$ depuis 4 ans dans l'Ouest de la France. C.R. $7^{\circ}$ Conf. Tris. E.A.P.R., Varsovie, 242-243.

Robert Y., Rouzé-Jouan J., 1976a. Activité saisonnière de vol des pucerons (Hom. Aphididae) dans l'Ouest de la France. Résultats de neuf années de piégeage (1967-1975). Ann. Soc. Entomol. Fr. (N.S.), $12(4), 671-690$.

Robert Y., Rouzé-Jouan J., 1976b. Neuf ans de piégeage de pucerons des céréales: Acyrthosiphon (Metopolophium) dirhodum Wlk. A. (M.) festucae Wlk. Macrosiphum (Sitobion) avenae F., M. (S.) fragariae Wlk. et Rhopalosiphum padi L. en Bretagne. Rev. Zool. Agric. Pathol. Vég., 75, 67-80.

Robert Y., Rouzé-Jouan J., 1978. Recherches écologiques sur les pucerons Aulacorthum solani Kltb., Macrosiphum euphorbiae Thomas et Myzus persicae Sulz. dans l'Ouest de la France. I. Etude de l'activité de vol de 1967 à 1976 en culture de pomme de terre. Ann. Zool. Ecol. Anim., 10 (2), 171-185.

Robert Y., Rabasse J.M., Rouzé-Jouan J., 1974. Sur l'utilisation des pièges jaunes pour la capture de pucerons en culture de pomme de terre. I. Influence de la hauteur de piégeage. Ann. Zool. Ecol. Anim., 6 (3), 349-372.

Wolda H., 1978. Seasonal fluctuations in rainfall, food and abundance of tropical insects. J. Anim. Ecol., 47, 369-381.

Wolda H., 1979. Fluctuaciones en la abundancia de insectos en el bosque tropical. Actas IV Symp. Int. Ecol. Trop. Panama (1977), 2, 519-539. 